\title{
Cycloartane-type sapogenol derivatives inhibit NFkB activation as chemopreventive strategy for inflammation-induced prostate carcinogenesis
}

\author{
Bilge Debeleç-Bütüner ${ }^{\mathrm{a}, *}$, Mert Burak Öztürk ${ }^{\mathrm{b}, 1}$, Özgür Tağ ${ }^{\mathrm{c}}$, İsmail Hakkı Akgün ${ }^{\mathrm{d}}$, \\ Günay Yetik-Anacak ${ }^{\mathrm{e}}$, Erdal Bedir ${ }^{\mathrm{d}, 2, *}$, Kemal Sami Korkmaz \\ ${ }^{\text {a }}$ Ege University, Faculty of Pharmacy, Department of Pharmaceutical Biotechnology, Izmir, Turkey \\ ${ }^{\mathrm{b}}$ Ege University, Faculty of Engineering, Department of Bioengineering, Cancer Biology Laboratory, Izmir, Turkey \\ ${ }^{\mathrm{c}}$ Ege University, Graduate School of Natural and Applied Sciences, Department of Chemistry, Izmir, Turkey \\ ${ }^{\mathrm{d}}$ Ege University, Faculty of Engineering, Department of Bioengineering, Izmir, Turkey \\ ${ }^{\mathrm{e}}$ Ege University, Faculty of Pharmacy, Department of Pharmacology, Izmir, Turkey
}

\section{A R T I C L E I N F O}

\section{Keywords:}

Astragenol

Cycloastragenol

Semi-synthesis

Prostate cancer chemoprevention

Inflammation-induced carcinogenesis

NFKB

\begin{abstract}
A B S T R A C T
Chronic inflammation is associated to $25 \%$ of cancer cases according to epidemiological data. Therefore, inhibition of inflammation-induced carcinogenesis can be an efficient therapeutic approach for cancer chemoprevention in drug development studies. It is also determined that anti-inflammatory drugs reduce cancer incidence. Cell culture-based in vitro screening methods are used as a fast and efficient method to investigate the biological activities of the biomolecules. In addition, saponins are molecules that are isolated from natural sources and are known to have potential for tumor inhibition. Studies on the preparation of analogues of cycloartane-type sapogenols (9,19-cyclolanostanes) have so far been limited. Therefore we have decided to direct our efforts toward the exploration of new anti-tumor agents prepared from cycloastragenol and its production artifact astragenol. The semi-synthetic derivatives were prepared mainly by oxidation, condensation, alkylation, acylation, and elimination reactions. After preliminary studies, five sapogenol analogues, two of which were new compounds (2 and 3), were selected and screened for their inhibitory activity on cell viability and NFKB signaling pathway activity in LNCaP prostate cancer cells. We found that the astragenol derivatives $\mathbf{1}$ and $\mathbf{2}$ as well as cycloastragenol derivatives $\mathbf{3}, \mathbf{4}$, and $\mathbf{5}$ exhibited strong inhibitory activity on NFkB signaling leading the repression of $\mathrm{NF \kappa B}$ transcriptional activation and suppressed cell proliferation. The results suggested that these molecules might have significant potential for chemoprevention of prostate carcinogenesis induced by inflammatory NFKB signaling pathway.
\end{abstract}

\section{Introduction}

Experimental and clinical studies demonstrate that anti-inflammatory drugs reduce the incidence of various types of cancer, in particular prostate, colon, and stomach [1]. In prostate cancer, regular use of aspirin and NSAIDs was determined to decrease the cancer risk about $15-20 \%$ in prospective and case control studies [2]. Most antiinflammatory agents show their anticancer effect through cellular mechanisms via inhibition of $\mathrm{NF \kappa B}, \mathrm{COX} 2$, and prostaglandin synthesis [2-6].

Chronic inflammation alters the cellular levels of reactive oxygen and nitrogen species (RONS), inflammatory cytokines, and other inflammatory mediators such as cyclooxygenase-2 (COX2), and also activates proto-oncogenes in the meanwhile. However, cellular response to inflammatory mechanisms can be pro- or anti-tumorigenic depending on the balance between inflammatory mediators in a cell [2].

One of the most important mediators of inflammation is NFKB, which is a transcription factor and the key molecule of pro-inflammatory signaling leading tumorigenesis. While some of NFKB transcriptional targets activate the cell cycle, angiogenesis, and metastasis, a group of targets inhibit apoptotic genes. Furthermore, many gene products of NFKB targets can be counted as mediators of innate

\footnotetext{
* Corresponding authors at: Ege University, Faculty of Pharmacy, Department of Pharmaceutical Biotechnology, Izmir, Turkey (B. Debeleç-Bütüner); Ege University, Faculty of Engineering, Department of Bioengineering, Izmir, Turkey (E. Bedir).

E-mail addresses: bilge.debelec@ege.edu.tr (B. Debeleç-Bütüner), erdalbedir@iyte.edu.tr (E. Bedir).

${ }^{1}$ Present address: Division of Cancer Genetics and Therapeutics, Laboratory of NFkB Signaling, Institute of Molecular and Cell Biology (IMCB), A*STAR (Agency for Science, Technology and Research), Singapore 138673, Singapore.

${ }^{2}$ Present address: Izmir Institute of Technology, Faculty of Engineering, Department of Bioengineering, Izmir, Turkey.
} 
immune response and inflammation, such as cytokines, chemokines, proteases including the NOS2, and COX2 [7,8]. Cytokines are key molecules of inflammation and immune response. The balance between pro- and anti-inflammatory cytokines determines the ultimate effect on cellular mechanisms leading to tumor growth or the inhibition. However, uncontrolled and sustained productions of pro-inflammatory cytokines result in tumorigenic alterations in cellular mechanisms functioning in cell proliferation, differentiation and apoptosis. In addition, pro-inflammatory NFKB pathway is activated by TNF- $\alpha$, of which moderate levels also lead to tumorigenesis $[2,7]$.

Infection and chronic inflammation are determined to be a significant cause of many cancer types [7,9-11]. Therefore, many chronic inflammatory diseases result in increased cancer risk. Long-term use of NSAIDs is found to be marginally correlated to decreased risk of breast, colon, prostate, lung and stomach cancer cases [12-14]. Additionally, in clinical studies investigating ROS level alterations and cancer risk due to the regular use of antioxidants, daily use of $50 \mathrm{mg}$ vitamin $\mathrm{E}$ is also determined to be effective on reduced prostate cancer incidence (32\%) and mortality (41\%). Negative correlation between use of antiinflammatory drugs and cancer risk clearly shows the role of active inflammation on stimulating carcinogenesis that might be possible to be inhibited [2].

Natural products provide a wide source for drug development studies, and the strategy of synthesizing semi-synthetic derivatives of secondary metabolites by chemical modifications leads to higher structural diversity. Saponins are polar glycosylates, which consist of triterpene/steroid aglycone with one or more sugar chains. They have a wide range of biological activity such as hemolytic, antimicrobial, antifungal, anti-inflammatory, antiviral, cytotoxic and antitumoral in literature $[15,16]$. Triterpenoids have a significant role in the regulation of inflammation. Many triterpenic structures such as avicine, astragalosides, betulin, betulinic acid, oleandrin, oleanolic acid and saikosaponins show a suppressor effect on NFKB signaling pathway [17]. In addition, less studied cycloartane-type saponins with low molecular weight are suggested as potential antitumor molecules since they are bioregulators inhibiting NFkB pathway $[18,19]$.

In this study, we aimed to prepare semi-synthetic analogs of cycloastragenol and astragenol and to investigate the potential anti-inflammatory activity of the selected compounds (1-5) by bioactivity studies including inhibition of NFKB signaling and cell proliferation on LNCaP prostate cancer cells.

\section{Experimental}

\subsection{Derivatization of cycloastragenol and astragenol}

\subsubsection{Cycloastragenol (CA)}

$(20 R, 24 S)-3 \beta, 6 \alpha, 16 \beta, 25$-tetrahydroxy-20,24-epoxy-9,19-cyclolanostane: CA ( $98 \%$ purity) was donated by Bionorm Natural Products (Turkey) [20].

\subsubsection{Astragenol $(A G)$}

$((20 R, 24 S)-3 \beta, 6 \alpha, 16 \beta, 25$-tetrahydroxy-20,24-epoxy-lanost-9(11)ene): AG was synthesized from $980 \mathrm{mg}(2.0 \mathrm{mmol})$ of cycloastragenol, which was dissolved in $\mathrm{MeOH}(50 \mathrm{~mL})$, then treated with conc. $\mathrm{H}_{2} \mathrm{SO}_{4}$ $(5 \mathrm{~mL})$. The whole mixture was heated under reflux for $6 \mathrm{~h}$. The reaction mixture was poured into water $(250 \mathrm{~mL})$ and was extracted three times with $250 \mathrm{~mL}$ EtOAc. The EtOAc extracts were washed successively with sat. $\mathrm{NaHCO}_{3}$ aq. $(250 \mathrm{~mL})$ then water $(250 \mathrm{~mL})$, and dried over $\mathrm{Na}_{2} \mathrm{SO}_{4}$ and filtered. The filtrates were evaporated and chromatographic separation of the crude products on a silica gel column was performed by using n-hexane:EtOAc (6:4) to give AG (63.9 mg lyophilized white powder, $65.2 \%$ yield) [20].

\subsubsection{Compound 1}

(Astragenol-3,6-diacetate) $\quad((20 R, 24 S)-3 \beta, 6 \alpha, 16 \beta, 25$-tetrahydroxy- 20,24-epoxy-lanost-9(11)-ene-3,6-diacetate): To a solution of AG $(50 \mathrm{mg}, 0.102 \mathrm{mmol})$ in pyridine $(5 \mathrm{~mL})$ at $25^{\circ} \mathrm{C}$, acetic anhydride $(250 \mu \mathrm{L})$ was added. The reaction mixture was stirred at room temperature for $12 \mathrm{~h}$, quenched with water $(50 \mathrm{~mL})$ and extracted three times with $50 \mathrm{~mL}$ EtOAc. The organic layers were dried over $\mathrm{Na}_{2} \mathrm{SO}_{4}$, filtered and concentrated. The residue was then purified on a silica gel column chromatography (n-hexane: EtOAc; 8:2) to produce 1 (6.62 mg lyophilized white-off powder, $11.4 \%$ yield) [20].

\subsubsection{Compound 2}

((20S,24S)-25-hydroxy-20,24-epoxy-lanost-9(11)-ene-3,6,16trione): To a stirring solution of AG $(100 \mathrm{mg}, 0.02 \mathrm{mmol})$ in acetone $(100 \mathrm{~mL})$, the Jones reagent $(0.4 \mathrm{~mL}, 3.3 \mathrm{mmol})$ was added slowly at ice bath, and stirred till completion of the reaction. After adding sat. $\mathrm{NaHCO}_{3}$ aq. $(100 \mathrm{~mL})$, the aqueous mixture was extracted three times with $25 \mathrm{~mL}$ dichloromethane. The combined organic layers were washed with brine solution, dried over $\mathrm{Na}_{2} \mathrm{SO}_{4}$, and filtered. The filtrate was evaporated, and chromatographic separation of the crude product on a silica gel column was performed by using n-hexanes:EtOAc (8:2) as eluent to give 2a $(74.7 \mathrm{mg}$ lyophilized white powder, $74.7 \%$ yield) [21]. 2a (3,6,16-trioxo-astragenol) (120 mg) was dissolved in $8 \mathrm{~mL}$ THF and was added NaOMe $(135 \mathrm{mg})$ at room temperature. The reaction mixture was stirred overnight, and sat. aq. $\mathrm{NaHCO}_{3}$ was added to the solution. The aqueous mixture was extracted three times with $25 \mathrm{~mL}$ dichloromethane. The combined organic layers were washed with brine solution, and dried over $\mathrm{Na}_{2} \mathrm{SO}_{4}$ and filtered. The filtrate was evaporated, and the crude product was purified on a silica gel column chromatography (n-hexane:EtOAc; 9:1) to give 2 (19.2 mg lyophilized white-off powder, $19.2 \%$ yield).

\subsubsection{Compound 3}

(Cycloastragenol-3,6-dipropionate) $((20 R, 24 S)-3 \beta, 6 \alpha, 16 \beta, 25$-tetrahydroxy-20,24-epoxy-9,19-cyclolanostane-3,6-dipropionate): $\quad 400 \mu \mathrm{L}$ propionic anhydride $(3.12 \mathrm{mmol})$ was added dropwise to a solution of CA $(100 \mathrm{mg}, 0.203 \mathrm{mmol})$ and $5 \mathrm{mg}$ DMAP $(0.04 \mathrm{mmol})$ in pyridine $(10.0 \mathrm{~mL})$. The reaction mixture was heated under reflux for $12 \mathrm{~h}$. The solution of completed reaction mixture was added to the cold $1 \mathrm{M} \mathrm{HCl}$ solution $(100 \mathrm{~mL})$, and it was extracted four times with $25 \mathrm{~mL} \mathrm{CHCl}_{3}$. Combined organic layers were dried over $\mathrm{Na}_{2} \mathrm{SO}_{4}$ and filtered. The filtered organic layers were evaporated under vacuum, and the crude product was purified on a silica gel flash chromatography column (nhexane:EtOAc; 4:1) to afford 3 (60 mg lyophilized white-off powder, $49 \%$ yield).

\subsubsection{Compound 4}

(Cycloastragenol-3,6-diacetate) $\quad((20 R, 24 S)-3 \beta, 6 \alpha, 16 \beta, 25$-tetrahydroxy-20,24-epoxy-9,19-cyclolanostane-3,6-diacetate): $200 \mu \mathrm{L}$ acetic anhydride $(2.112 \mathrm{mmol})$ was added dropwise to a solution of CA $(100 \mathrm{mg}, 0.203 \mathrm{mmol})$ and $5 \mathrm{mg}$ DMAP $(0.04 \mathrm{mmol})$ in pyridine $(10.0 \mathrm{~mL})$. The reaction mixture was heated under reflux for $12 \mathrm{~h}$. The solution of completed reaction mixture was added to the cold $1 \mathrm{M} \mathrm{HCl}$ solution $(100 \mathrm{~mL})$, and it was extracted four times with $25 \mathrm{~mL} \mathrm{CHCl}_{3}$. Combined organic layers were dried over $\mathrm{Na}_{2} \mathrm{SO}_{4}$ and filtered. The filtered organic layers were evaporated under vacuum and the crude product was purified on a silica gel flash chromatography column (nhexane:EtOAc; 7:3) to afford 4 (50 mg lyophilized white-off powder, $48 \%$ yield) [22].

\subsubsection{Compound 5}

(Cycloastragenol-6-acetate) ( $(20 R, 24 S)-3 \beta, 6 \alpha, 16 \beta, 25$-tetrahydroxy20,24-epoxy-9,19-cyclolanostane-6-acetate): $100 \mu \mathrm{L}$ acetic anhydride $(2.112 \mathrm{mmol})$ was added dropwise to a solution of CA $(100 \mathrm{mg}$, $0.203 \mathrm{mmol})$ and $5 \mathrm{mg}$ DMAP $(0.04 \mathrm{mmol})$ in pyridine $(10.0 \mathrm{~mL})$. The reaction mixture was heated under reflux for $12 \mathrm{~h}$. The solution of completed reaction mixture was added to the cold $1 \mathrm{M} \mathrm{HCl}$ solution $(100 \mathrm{~mL})$, and it was extracted four times with $25 \mathrm{~mL}$ chloroform. 
Combined organic layers were dried over $\mathrm{Na}_{2} \mathrm{SO}_{4}$ and filtered. The filtered organic layers were evaporated under vacuum and the crude product was purified on a silica gel flash chromatography column (nhexane:EtOAc; 5:5) to afford 5 (24 mg lyophilized white-off powder, $23 \%$ yield) [23].

\subsection{Cell culture and treatments}

The LNCaP, PC3, RWPE-1 and RAW264.7 cells were obtained from American Type Culture Collection (ATCC Manassas, VA). LNCaP and RAW264.7 cells were propagated using RPMI 1640 supplemented with $10 \%$ FBS, L-glutamine $(2 \mathrm{mM})$, penicillin $(100 \mathrm{U} / \mathrm{mL})$ and streptomycin $(100 \mu \mathrm{g} / \mathrm{mL})$, and PC3 cells were propagated using DMEM F-12 supplemented with $5 \%$ FBS, L-glutamine $(2 \mathrm{mM})$, penicillin $(100 \mathrm{U} / \mathrm{mL})$ and streptomycin $(100 \mu \mathrm{g} / \mathrm{mL})$ while RWPE-1 cells were propagated in Keratinocyte growth medium supplemented with bovine pituitary extract and $5 \mu \mathrm{M}$ EGF at $37{ }^{\circ} \mathrm{C}$ with $5 \% \mathrm{CO}_{2}$. FBS used for RAW264.7 cells were inactivated for $1 \mathrm{~h}$ with usual conditions of serum inactivation. BAY11-7082 (Sigma-Aldrich), celocoxib (Sigma-Aldrich), lipopolysaccharide (Sigma-Aldrich), and recombinant TNF- $\alpha$ (Roche) were used at the recommended concentrations according to the literature. Molecules were dissolved in DMSO and treatments were done as DMSO volume will not exceed $0.5 \%$ of the culture media volume. Control cells were treated with the same volume of DMSO used during the molecule treatments. $\mathrm{IC}_{50}$ concentrations of the molecules were calculated through nonlinear regression analysis of Graphpad Prism 6. IC 10 and $\mathrm{IC}_{20}$ concentrations were calculated by using the following formula where ECF is the interested inhibitory concentration, $\mathrm{F}$ is the interested cell viability percent and $\mathrm{H}$ is the hill slope: $\mathrm{ECF}=[\mathrm{F} /(100-\mathrm{F})] 1 / \mathrm{H}$ $* \mathrm{EC}_{50}$

\subsection{Conditioned media (CM) collection and measurement of cytokines in $C M$}

The U937 monocyte cell line was cultured in RPMI 1640 medium with $10 \% \mathrm{FBS}$ (fetal bovine serum) at $37^{\circ} \mathrm{C}$ with $5 \% \mathrm{CO}_{2}$. To achieve macrophage differentiation and cytokine production, cells $(8 \times 106)$ were grown in $75 \mathrm{~cm}^{2}$ culture flasks for $2 \mathrm{~h}$ prior to treatment. Next, phorbol 12-myristate-13-acetate (PMA) was added at a final concentration of $16 \mathrm{nM}$ for $16 \mathrm{~h}$, and adherent clusters were followed. Cells were washed twice, and $20 \mathrm{~mL}$ of fresh medium was then added. After allowing the cells to rest for 2-3 h, lipopolysaccharide (LPS) was added ( $10 \mathrm{ng} / \mathrm{mL}$ ), and the cells were incubated for $24 \mathrm{~h}$. Finally, the supernatant (conditioned medium - CM) was collected and filtered $(0.2 \mu \mathrm{m})$ for further use.

Before feeding the LNCaP cells with CM, TNF- $\alpha$ (Invitrogen), interleukin-6 (IL-6) and interleukin-1beta (IL-1) (Boster Biological Technology Co., US) levels were assessed by ELISA according to the manufacturer's recommendations. Finally, CM with known concentrations of TNF- $\alpha$ was used to induce inflammatory microenvironment in cell culture [24].

\subsection{Antibodies}

The antibodies were purchased from the manufacturers as follows: the NFкB (p65), IкB, p-IкB (S32/36) antibodies were purchased from Cell Signaling Inc., USA; GAPDH antibody was purchased from Ambion, US. B-actin antibody was purchased from Sigma-Aldrich; COX1, COX2 and HRP-anti-goat antibodies were purchased from SCBT, Germany. The HRP-anti-mouse and HRP-anti-rabbit secondary antibodies were purchased from Amersham, UK and used as recommended.

\subsection{WST1 proliferation assay}

LNCaP $\left(10^{4}\right)$ cells were seeded and grown in 96-well plates and incubated for $48 \mathrm{~h}$. Molecule treatments were performed for $24 \mathrm{~h}$ and
WST1 cell proliferation reagent (Roche Cat No: 05015944001) was used as recommended. Briefly, WST1 (1:10 final dilution) was added onto the cells at the end of treatments, and the cells were incubated for an additional $3 \mathrm{~h}$. At the end of the incubation, absorbance measurements at 450 and $690 \mathrm{~nm}$ reference wavelengths were performed to calculate the growth rate.

\section{6. $N F \kappa B$ luciferase reporter assay}

LNCaP cells $\left(10^{4}\right)$ were seeded in 96-well culture plates and incubated for $48 \mathrm{~h}$. Cell culture media was replaced with serum/antibiotics free culture medium $2 \mathrm{~h}$ before the transfection. Negative and positive control vectors $(100 \mathrm{ng} / \mathrm{mL})$, and $\mathrm{NF \kappa B}(100 \mathrm{ng} / \mathrm{mL})$ reporter vector (SABiosciences Cignal NFkB reporter luc kit-CCS-013L) were transfected by Fugene HD transfection reagent (Roche). Normal culture medium was added onto cells $5 \mathrm{~h}$ after transfection, and incubated for a total $24 \mathrm{~h}$. Treatments were performed for $4 \mathrm{~h}$ and cells were collected with passive lysis buffer according to the recommendations of dualluciferase reporter assay kit (Promega, UK). Renilla/firefly luciferase activity measurements were performed by luminometer (Thermo) according to manufacturer's protocol.

\subsection{Nuclear-cytoplasmic fractionation}

LNCaP cells $\left(10^{6}\right)$ were rinsed, scraped into cold PBS and then centrifuged at $300 \mathrm{~g}$ for $5 \mathrm{~min}$. The pellets were suspended in $250 \mu \mathrm{L}$ buffer A (50 mM HEPES pH 7.4, $10 \mathrm{mM} \mathrm{KCl,} 1$ mM EDTA, 1 mM EGTA with freshly added $1 \mathrm{mM}$ DDT, protease and phosphatase inhibitors) and incubated on a rotator for $30 \mathrm{~min}$. Next, the samples were centrifuged at $4000 \mathrm{~g}$ for $30 \mathrm{~min}$, and the supernatant (cytoplasmic extract) was collected. The cell pellet was washed four times with buffer A and centrifuged again at $4000 \mathrm{~g}$ for $5 \mathrm{~min}$. After washing, the pellet was resuspended in $250 \mu \mathrm{L}$ buffer B (50 mM HEPES pH 7.4, 1 mM EDTA, $1 \mathrm{mM}$ EGTA, $400 \mathrm{mM} \mathrm{KCl}$, and $0.5 \%$ Triton X-100 with freshly added $1 \mathrm{mM}$ DDT, protease and phosphatase inhibitors) and incubated on a rotator for $30 \mathrm{~min}$. Centrifugation was performed at $14,000 \mathrm{~g}$ for $30 \mathrm{~min}$, and the supernatant (nuclear extract) was collected. All incubations and centrifugations were performed at $4{ }^{\circ} \mathrm{C}$.

\subsection{Cell lysis, protein extraction and blotting}

For protein extraction, cells were grown in 6-cm plates (Sarstedt, Germany) and washed once with PBS prior to cell lysis. Next, $250 \mu \mathrm{L}$ ice-cold modified RIPA buffer ( $10 \mathrm{mM}$ Tris $\mathrm{Cl}(\mathrm{pH} 8.0), 1 \%$ Triton X$100,0.1 \%$ SDS, $0.1 \%$ Na deoxycholate, $1 \mathrm{mM}$ EDTA, 1 mM EGTA and $140 \mathrm{mM} \mathrm{NaCl}$ ) containing both protease and phosphatase inhibitors was added to the plates, and the cells were then collected into eppendorf tubes using a cell scraper. The lysates were sonicated for 20 s $(25 \%$ power, 0.5 cycles), centrifuged at $12000 \mathrm{~g}$ for $10 \mathrm{~min}$ at $4{ }^{\circ} \mathrm{C}$, and the cleared supernatants were transferred into new tubes. The protein concentration was determined using a BCA assay (Sigma, UK). Western blots were performed under standard conditions using $50 \mu \mathrm{g}$ of protein lysate per lane. First, the proteins were separated on a $10-12 \%$ SDSPAGE gel, and transferred to a PVDF membrane (Amersham, UK) using a wet transfer blotter. The PVDF membrane was blocked with $5 \%$ dry milk in TBS-T (Tris-Borate-Saline solution containing 0.1\% Tween 20), and then primary and secondary antibody incubations were performed using TBS-T containing $0.5 \%$ dry milk or $5 \%$ BSA at RT for $1 \mathrm{~h}$ or at $4{ }^{\circ} \mathrm{C}$ overnight. The membranes were developed using ECL plus reagent (Amersham, UK) for $5 \mathrm{~min}$, and were photographed using Kodak X-Ray films in a dark room.

\subsection{Total RNA isolation and cDNA preparation}

Total RNA was isolated from cultured LNCaP cells using RNeasy kit (Qiagen, CA). The yield was calculated by using absorbance readings at 
Table 1

Primer pairs used for qRT-PCR amplification.

\begin{tabular}{lll}
\hline TNFa & Forward & GAGGCCAAGCCCTGGTATG \\
& Reverse & CGGGCCGATTGATCTCAGC \\
COX2 & Forward & CCCTTGGGTGTCAAAGGTAA \\
& Reverse & GCCCTCGCTTATGATCTGTC \\
ICAM1 & Forward & AGGGTAAGGTTCTTGCCCAC \\
& Reverse & TGATGGGCAGTCAACAGCTA \\
GAPDH & Forward & CATTGCCCTCAACGACCACTTT \\
& Reverse & GGTGGTCCAGGGGTCTTACTCC
\end{tabular}

260/280 nm. Additionally, cDNA synthesis was performed using Superscript III cDNA kit (Invitrogen) according to the recommendations of the manufacturers.

\subsection{Quantitative real time $P C R$}

To examine the gene expression level, quantitative RT-PCR was performed using a SYBR Green PCR kit and the LC480 PCR system (Roche, Germany). The relative abundance of each transcript was calculated using the comparative cycle of threshold (CT) method with GAPDH as an invariant control. The primers utilized are given in Table 1.

\subsection{Measurement of PGE2 level}

RAW264.7 macrophages $\left(4 \times 10^{4}\right)$ were seeded to 96-well plate and incubated for $24 \mathrm{~h}$. Molecule treatments were performed and cell culture media was collected for further use in PGE2 Elisa kit (Cayman Chemicals). PGE2 concentration in supernatant was measured as $\mathrm{pg} / \mathrm{mL}$ as recommended.

\subsection{Real-time cell proliferation assay}

The Xcelligence proliferation assay platform was used for real-time measurements. Briefly, the LNCaP cells $\left(1 \times 10^{4}\right)$ were seeded into 96well plates (E-plates, Roche GmbH, Germany) and the treatments were performed. Proliferation rate were monitored by impedance values collected every $15 \mathrm{~min}$ for $48 \mathrm{~h}$

\subsection{Statistics}

Data are presented as means \pm standard deviation (SD). The Student's $t$ test with two-tailed equal variance was applied to assess the statistical significance between pairs when necessary. $\mathrm{P}<0.05$ was accepted as significant

\section{Results}

In order to find a potent anti-inflammatory molecule that can be a candidate for chemoprevention of inflammation-induced prostate cancer, a compound library was prepared from astragenol and cycloastragenol by semi-synthesis studies. A number of analogs, prepared mainly by acylation and oxidation reactions, and structurally elucidated by spectral methods $\left({ }^{1} \mathrm{H},{ }^{13} \mathrm{C}\right.$ NMR and HR-MS; data is shown in the Supplementary part), were screened for cytotoxicity by WST1 and for NFKB inhibition activity by luciferase reporter assay on LNCaP prostate cancer cells (data not shown). The most potent five molecules, two of which were new (2 and 3), were selected for further studies (1-5). The structures and syntheses routes are shown in Fig. 1. To characterize the anti-inflammatory activity of the selected molecules, $\mathrm{NF \kappa B}$ inhibitory activity and molecular mechanisms of the inhibition experiments were performed.

\subsection{Structure elucidation of the new compounds (2 and 3)}

Compound 2a was obtained from an oxidation reaction of AG. At $0{ }^{\circ} \mathrm{C}$, Jones oxidation resulted in $\mathbf{2 a}$ in $64 \%$ yield as previously described [21].

Treatment of 2a with sodium methoxide in THF provided compound 2. The HRESIMS data of 2 displayed no mass change $(\mathrm{m} / \mathrm{z}$ $467.3280[\mathrm{M}+\mathrm{Na}]^{+}$) compared to the starting molecule 2a. The NMR spectra of 2a and $\mathbf{2}$ were almost identical except for the tetrahydrofuran ring (20,24-epoxy side chain). Detailed inspection of the spectral data (1- and 2D NMR) revealed that 2 was formed through rearrangement of the side chain. In the ${ }^{13} \mathrm{C}$-NMR spectrum, the characteristic signals of C20 and C-24 are supposed to resonate $c a$. at $\delta 88.0$ and 82.5, respectively for CG, AG and 2a possessing 20R,24S absolute stereochemistry $[20,21]$. When ${ }^{13} \mathrm{C}-\mathrm{NMR}$ and HMQC spectra of $\mathbf{2}$ were examined together, an oxymethine carbon was located at $\delta 82.5$, whereas a quaternary carbon resonated at $\delta 84.5$. These two carbon resonances were assigned unambiguously to $\mathrm{C}-20$ and $\mathrm{C}-24$, respectively. These data implied stereochemical alteration at $\mathrm{C}-20$ position as $S$, in accordance with literature data of related natural products $[25,26]$. Such a semisynthetic rearrangement reaction in cycloartane (9,19-cyclolanostane) chemistry is being reported for the first time. A plausible mechanism for the transformation of $\mathbf{2 a}$ into the compound $\mathbf{2}$ was illustrated in Fig. 9.

Compound $\mathbf{3}$ was obtained from an esterification reaction of CA using propionic anhydride and DMAP in pyridine. ESI-MS spectrum showing a major ion peak at $m / z 625.3\left([\mathrm{M}+\mathrm{Na}]^{+}\right)$indicated a molecular formula of $\mathrm{C}_{36} \mathrm{H}_{58} \mathrm{O}_{7}$. In the ${ }^{1} \mathrm{H}$ NMR, the characteristic signals belonging to H-3 and H-6 were shifted to the downfield implying acylation positions. Also, two new methyl signals observed in the upfield region were assigned to the propionyl groups' terminal methyl groups. In addition, in the ${ }^{13} \mathrm{C}$ NMR spectrum, two carbons at 174.3 and 173.8 were readily attributed to the ester carbonyls. Thus, the structure of 3 was established as $((20 R, 24 S)-3 \beta, 6 \alpha, 16 \beta, 25$-tetrahydroxy-20,24epoxy-9,19-cyclolanostane-3,6-dipropionate.

\subsection{Cytotoxic activity on LNCaP prostate cancer cells}

Cytotoxic activity of the compounds on LNCaP prostate cancer cells was determined by WST1. Treatments were performed at $100 \mu \mathrm{M}$, $50 \mu \mathrm{M}, 25 \mu \mathrm{M}, 12.5 \mu \mathrm{M}$, and $6.25 \mu \mathrm{M}$ concentrations of the molecules dissolved in DMSO for $24 \mathrm{~h}$. Control cells were treated with the same volume of DMSO as vehicle. Relative cell viability results were calculated through normalization of treated cells to control cells.

Cytotoxic activities of the semi-synthetic molecules $\mathbf{1}$ and $\mathbf{2}$ were found to be higher than the starting compound AG (Fig. 2A), and IC 50 values were calculated as $20 \mu \mathrm{M}$ and $82 \mu \mathrm{M}$, respectively (Fig. 2B). In addition, CA analogs showed cytotoxic effects with IC $_{50}$ values of $14 \mu \mathrm{M}$ for $3,23 \mu \mathrm{M}$ for 4 , and $49 \mu \mathrm{M}$ for 5 (Fig. 3A). IC 50 values were calculated by Graphpad Prism and $\mathrm{IC}_{20}$ values were derived from $\mathrm{IC}_{50}$ as explained in methods section for further studies (Figs. 2B and 3B).

\subsection{Inhibition of $N F_{\kappa} B$ activity}

Since NFKB signaling pathway is suggested as a link between inflammation and tumorigenesis, inhibition of NFKB activity is a key therapeutic strategy to inhibit inflammation-induced carcinogenic mechanisms. To investigate NFKB inhibitory activity of the molecules on LNCaP cells, cells were transfected with NFKB luciferase reporter and control vectors for $24 \mathrm{~h}$. $\mathrm{IC}_{20}$ concentrations of the molecules and vehicle control were added onto cells w/wo $25 \mathrm{ng} / \mathrm{ml}$ TNF- $\alpha$ for $4 \mathrm{~h}$. NFkB activity was measured for each well and relative luciferase activity was determined by normalization of \% activity of TNF- $\alpha$-induced cells to non-induced cells. When NFKB activity was induced to 179 fold by TNF$\alpha$ treatment, molecules at indicated concentrations suppressed the activity to 98 (AG), 9.8 (1), and 55 (2) fold (Fig. 4A). Cycloastragenol and its derivatives led to a decrease to 42 (CA), 92 (3), 1.1 (4), and 4.7 (5) 


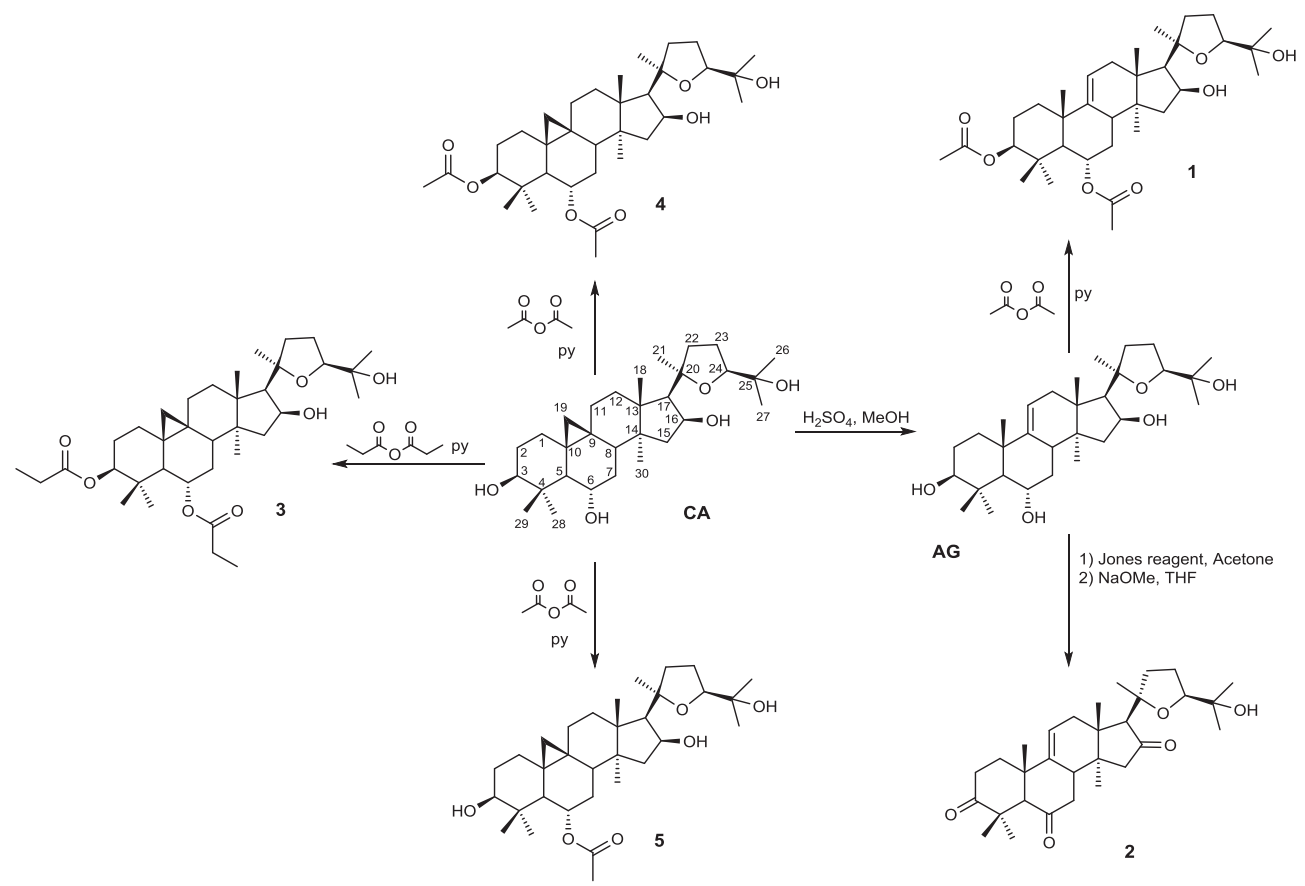

Fig. 1. Structures and preparation of 1-5 from CA and AG.

fold (Fig. 5A). Besides, specific NFkB inhibitor BAY11-7082 $(5 \mu \mathrm{g} / \mathrm{ml})$ was used as a positive control with the suppression activity up to 98 fold.

We subsequently aimed to characterize the inhibition mechanism of the molecules via inducing cells by either recombinant TNF- $\alpha$ as an $\mathrm{NF \kappa B}$ inducer or conditioned inflammatory microenvironment medium. In vitro inflammatory microenvironment model was previously developed and used in our laboratory to simulate prostatic inflammation-
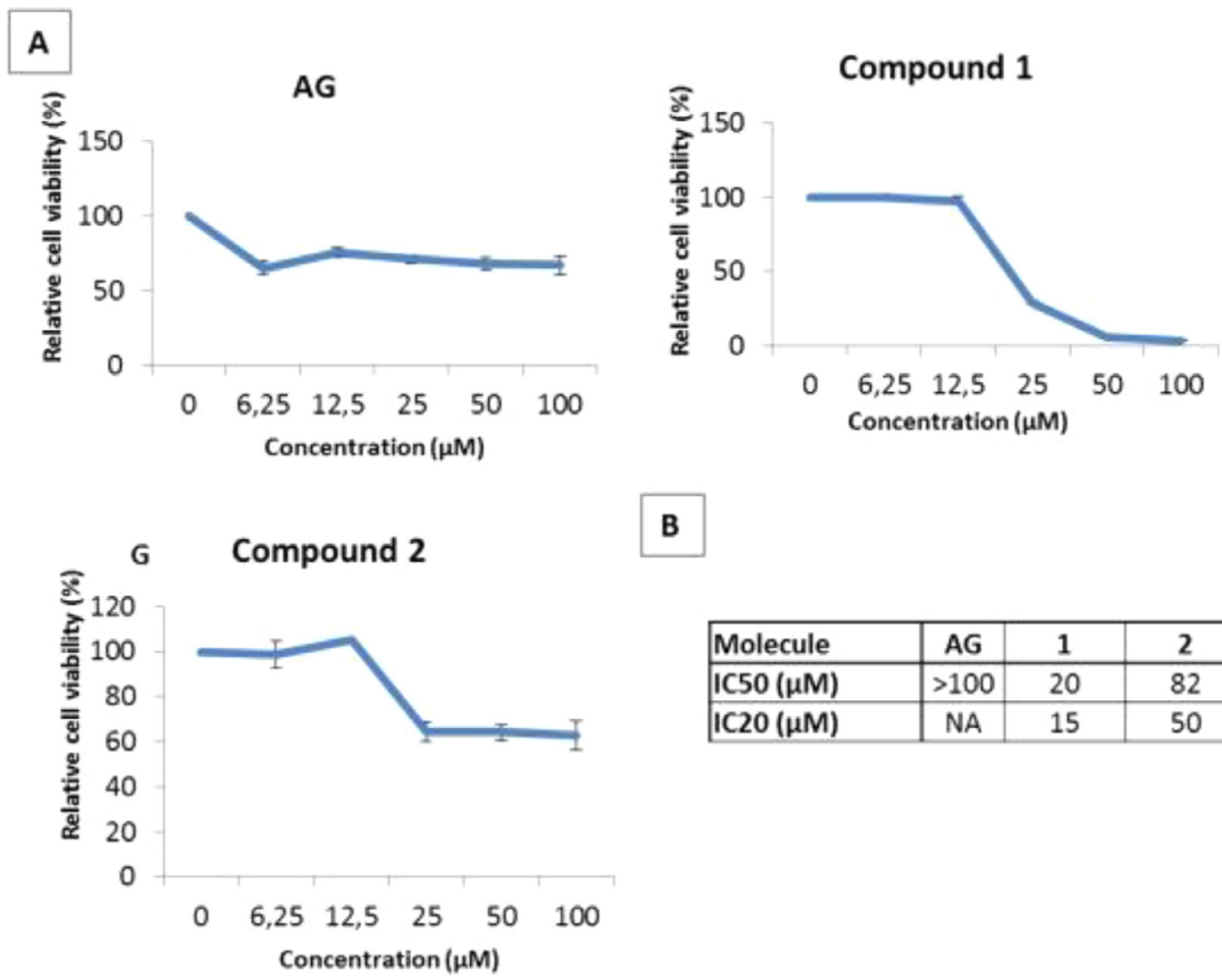

B

\begin{tabular}{|l|c|c|c|}
\hline Molecule & AG & $\mathbf{1}$ & $\mathbf{2}$ \\
\hline IC50 $(\mu \mathrm{M})$ & $>100$ & 20 & 82 \\
\hline IC $20(\mu \mathrm{M})$ & NA & 15 & 50 \\
\hline
\end{tabular}

Fig. 2. A. Viability of LNCaP cells $\left(10^{4}\right)$ was determined by WST1 method after treatment with increasing concentrations of the molecules $(6.25 \mu \mathrm{M}, 12.5 \mu \mathrm{M}, 25 \mu \mathrm{M}$, $50 \mu \mathrm{M}, 100 \mu \mathrm{M}$ ) for $24 \mathrm{~h}$. Relative cell viability was calculated through normalization of $\%$ cell viability at each concentration to untreated cells. Error bars represent the standart deviation of 3 replicates at each data point, $\mathrm{p}<0,01$; $\mathrm{B}$. $\mathrm{IC}_{50}$ concentrations of the molecules, and $\mathrm{IC}_{20}$ concentrations calculated through derivation from $\mathrm{IC}_{50}$ values of each molecule. 

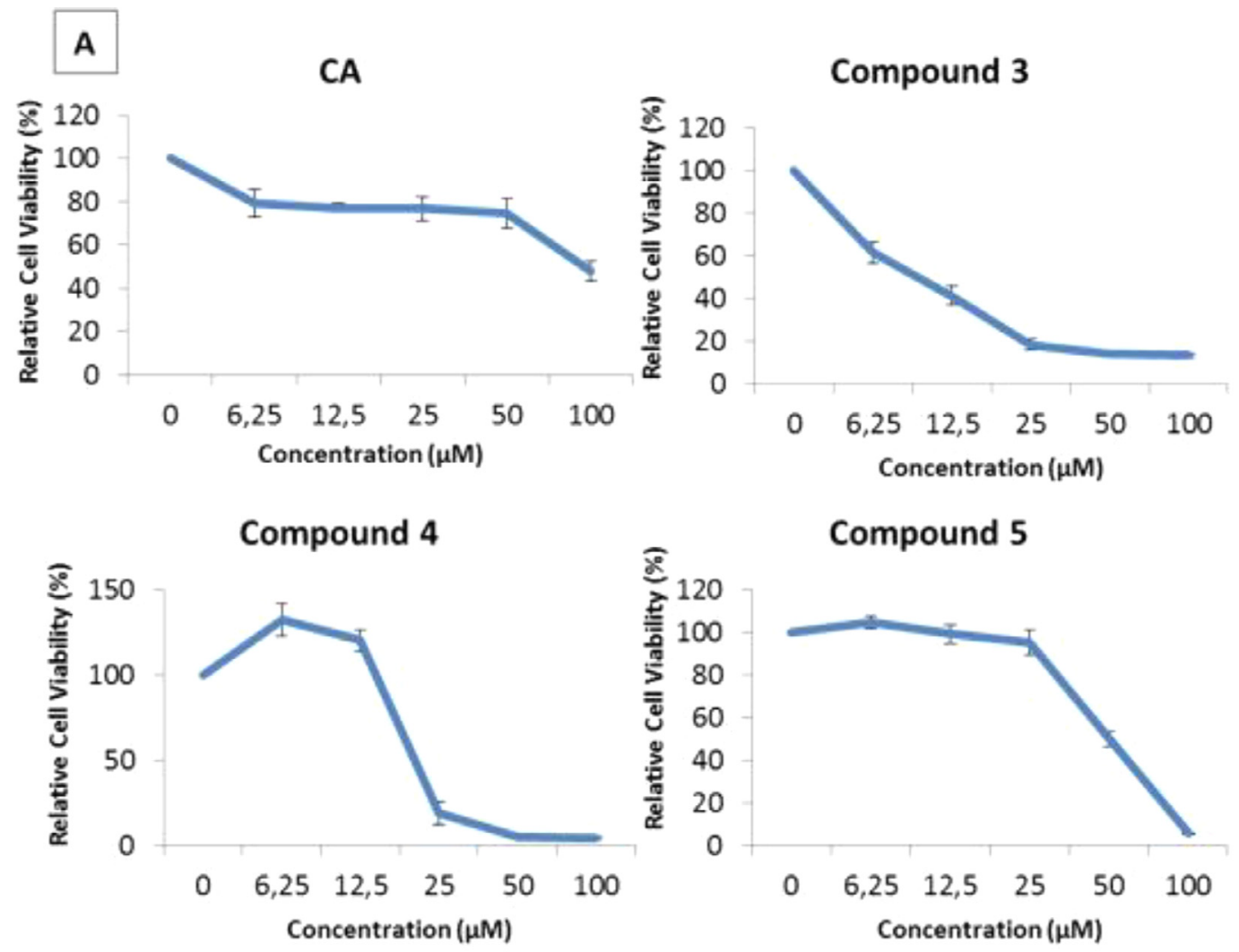

\section{B}

\begin{tabular}{|l|c|c|c|c|}
\hline Molecule & CA & $\mathbf{3}$ & $\mathbf{4}$ & $\mathbf{5}$ \\
\hline IC50 $(\mu \mathrm{M})$ & $>100$ & 14 & 23 & 49 \\
\hline IC20 $(\mu \mathrm{M})$ & NA & 5 & 20 & 30 \\
\hline
\end{tabular}

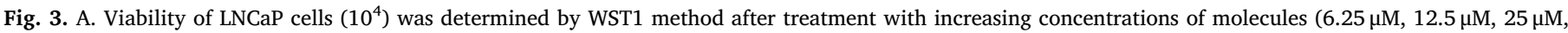

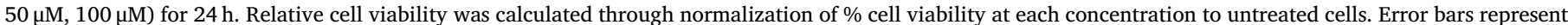

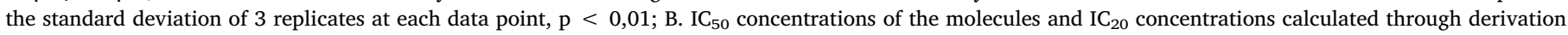
from $\mathrm{IC}_{50}$ values of each molecule.

induced tumor microenvironment in cell culture. Briefly, U937 monocytes are treated with PMA for differentiation to macrophages. Then, macrophages are stimulated with lipopolysaccharide to induce pro-inflammatory cytokine release. Lastly, this conditioned medium (CM) is collected, filtered and subjected to the measurement of cytokine levels in order to feed cancer cells by using CM with known cytokine concentrations. The levels of TNF- $\alpha$, IL1 $\beta$ and IL6 are determined by Elisa. In addition, differently from generally used conditioned media applications, after the cytokine concentration in CM is measured, CM is diluted with normal culture media to adjust the interested concentration of the cytokine at final inflammatory culture media as effect of TNF- $\alpha$ has been known to be in an opposite way from each other at relatively low and high concentrations [2,24].

High levels lead to cell death, whereas moderate levels result in activation of tumorigenic mechanisms. Therefore, to simulate the moderate levels of TNF- $\alpha$ as it occurs during chronic inflammation, concentration of TNF- $\alpha$ in CM is adjusted to appropriate levels according to the concept of the experiment as well as previous studies $[24,27]$. In this study, we also used this model to investigate the effects of the molecules against NFkB activation by inflammatory microenvironment as a supporting method of $\mathrm{NFKB}$ activation by recombinant cytokine.
When NFKB signaling pathway is stimulated, p65 subunit, which is present in a cytoplasmic protein complex with IкB, releases from the complex and translocates to nucleus in order to activate its transcriptional targets. Since its known that some of the specific NFKB inhibitors show their activity by preventing the translocation of free NFKB p65 subunit to nucleus after it released from the complex, this point of the signaling cascade has been checked. For this, subcellular fractionation was performed after LNCaP cells were treated with $40 \mathrm{ng} / \mathrm{ml}$ recombinant TNF- $\alpha$ for $4 \mathrm{~h}$ and nuclear/cytoplasmic NFkB p65 levels were detected by immunoblotting. Nuclear p65 level was shown to increase with TNF- $\alpha$ induction and partially reduce by $\mathbf{1}$ and $\mathbf{2}$. Complete inhibition of the translocation BAY11-7082 was also shown as a positive control (Fig. 4B).

In addition, NFkB can also show their effects by inhibition of any member of the signaling pathway [4]. To figure out the NFKB inhibition mechanism of the molecules, changes in protein levels and post-translational modifications of the NFKB pathway members were investigated. Since IкB $\alpha$ is localized in the cytoplasm as bound to NFKB and its phosphorylation as well as proteasomal degradation is induced due to the activation of NFKB pathway, and the degradation status and S32/36 phosphorylation of IкB was studied by either TNF- $\alpha$ induction or inflammatory conditioned media treatment in LNCaP cells. After 


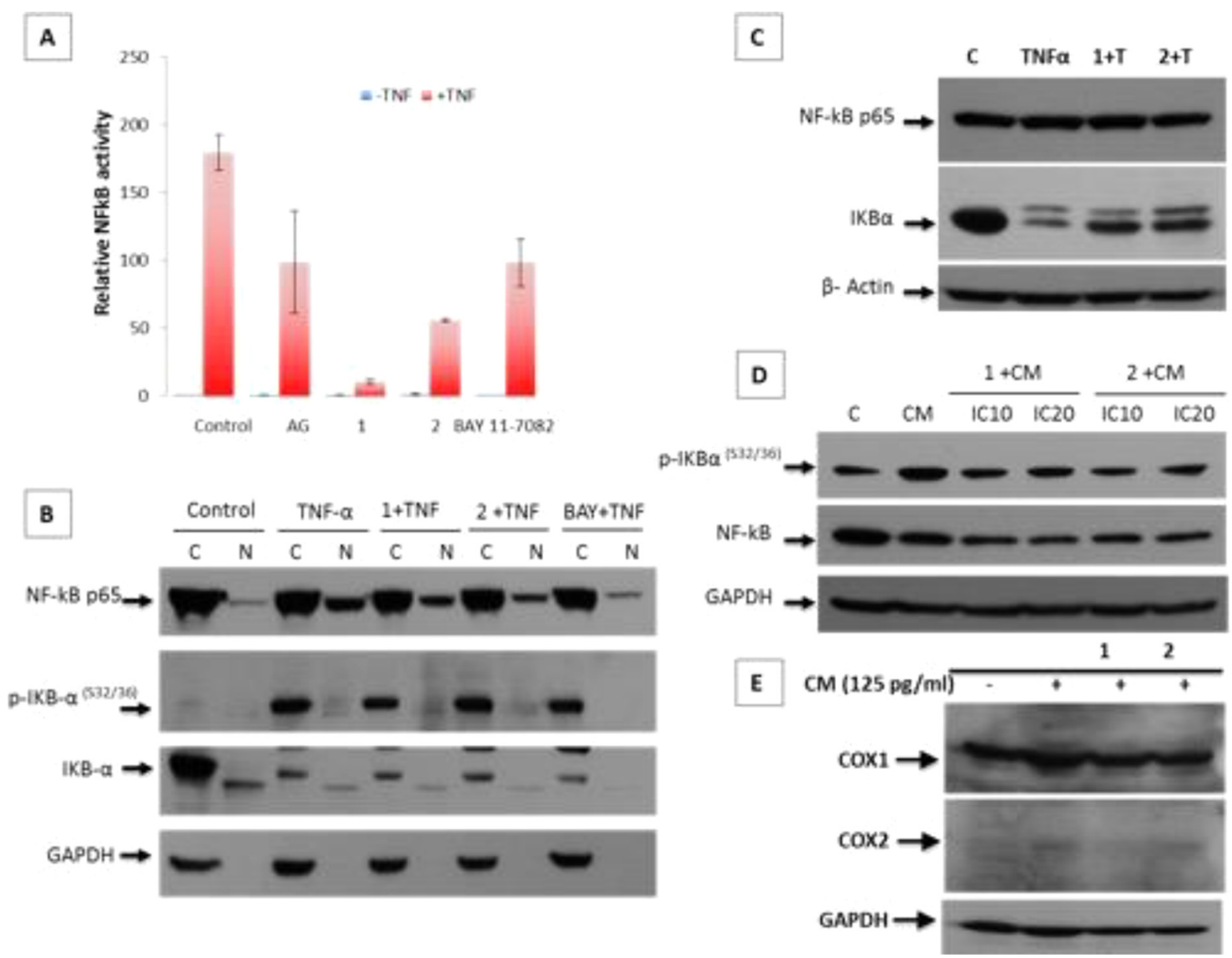

Fig. 4. A. Inhibitory effects of the molecules on NFKB signaling pathway in LNCaP cells were determined by NFkB luciferase reporter assay. $10^{4} \mathrm{LNCaP}$ cells were transfected with NFKB luciferase reporter vector and incubated for $48 \mathrm{~h}$. AG $(100 \mu \mathrm{M}), \mathbf{1}(15 \mu \mathrm{M})$ and $2(50 \mu \mathrm{M})$ were added onto cells w/wo recombinant TNF- $\alpha$ induction $(40 \mathrm{ng} / \mathrm{ml})$ for $4 \mathrm{~h}$. Dual luciferase activity was measured and relative luciferase activity was calculated as fold change of luciferase activity of TNF- $\alpha$ treated cells versus untreated cells after firefly/renilla normalization. Blue bars represent TNF- $\alpha$ untreated and red bars represent TNF treated cells. Error bars represent the standard deviation of 3 replicates, $\mathrm{p}<0,001$; B. LNCaP cells $\left(7,5 \times 10^{5}\right)$ were treated with recombinant TNF- $\alpha(40 \mathrm{ng} / \mathrm{ml}) \mathrm{w} / \mathrm{wo} 1(15 \mu \mathrm{M})$ and 2 $(50 \mu \mathrm{M})$ and BAY11-7082 $(5 \mu \mathrm{g} / \mathrm{ml})$ for $4 \mathrm{~h}$. Cytoplasmic and nuclear fractions were isolated and subcellular protein levels of NFKB p65 and IкB were determined by western blot. GAPDH blotting and polyacrylamide gel staining (not shown) were used as loading control. BAY11-7082 treatment was performed as a positive control of NFKB specific inhibition; C and D. Effects of the molecules on $\mathrm{NFKB}$ pathway proteins were determined by western blot after the treatment of $4 \times 10^{5} \mathrm{LNCaP}$ cells with (C) TNF- $\alpha(40 \mathrm{ng} / \mathrm{ml})$ w/wo $1(15 \mu \mathrm{M})$ and $2(50 \mu \mathrm{M})$ for $4 \mathrm{~h}$ and (D) conditioned media (CM) including $125 \mathrm{pg} / \mathrm{ml} \mathrm{TNF- \alpha} \mathrm{w/wo} 1$ (IC 10 : $4 \mu \mathrm{M}, \mathrm{IC}_{20}: 15 \mu \mathrm{M}$,) and $2\left(\mathrm{IC}_{10}: 14 \mu \mathrm{M}, \mathrm{IC}_{20}: 50 \mu \mathrm{M}\right)$ of the molecules for $24 \mathrm{~h}$; E. Inhibition of COX1 and COX2 proteins were determined after treatment with conditioned media (CM) including $125 \mathrm{pg} / \mathrm{ml}$ TNF- $\alpha$ w/wo $1(15 \mu \mathrm{M})$ and $2(50 \mu \mathrm{M})$ for $24 \mathrm{~h}$. B-actin and GAPDH were used as loading controls.

cells were treated with TNF- $\alpha$ for $4 \mathrm{~h}$, TNF- $\alpha$-induced IкB degradation detected to be partially suppressed by $\mathbf{1}$ and $\mathbf{2}$ where the protein level of NFкB p65 unit remained unchanged (Fig. 4C). Further, to simulate the inflammatory microenvironment of the cell in vitro, inflammatory $\mathrm{CM}$ including $125 \mathrm{pg} / \mathrm{ml} \mathrm{TNF- \alpha}$ was applied onto cells w/wo molecules for $24 \mathrm{~h}^{\mathrm{I} \mathrm{IKB}^{(\mathrm{S} 32 / 36)}}$ level was observed to be enhanced by the CM treatment and decreased with increasing concentrations of the same molecules. However, NFKB protein level was observed to decrease due to the treatments possibly related to the cytotoxic effect of the molecules on cell proliferation (Fig. 4D). COX2 alteration in protein level was also checked in inflammatory microenvironment and its increased protein level after CM was repressed by $\mathbf{1}$ and $\mathbf{2}$, while no change was seen at COX1 level (Fig. 4E).

In addition, cycloastragenol derivatives were also investigated at the same experiment settings and decrease of nuclear NFkB p65 level was also determined in the presence of $\mathbf{3}, \mathbf{4}$, and 5 (Fig. 5B). Further, TNF- $\alpha$-induced IкB degradation was recovered by 3 , but not by 4 and 5 . $\mathrm{NF \kappa B}$ levels remained the same in the presence of 3 , however decreased by 4 and $\mathbf{5}$. Therefore, it is suggested that $\mathbf{4}$ and $\mathbf{5}$ not only repress NFkB signaling at these concentrations but also show further inhibitory effect on cell viability and still have a severe cytotoxic effect on cell survival
(Fig. 5C). Further, in inflammatory microenvironment, induced $\mathrm{IkB}^{(\mathrm{S} 32 /}$ ${ }^{36)}$ level was repressed partially by 3 and totally to the basal level by 4 and 5 (Fig. 5D). In addition, COX2 expression was repressed by all cycloastragenol derivatives without COX1 inhibition (Fig. 5E).

\subsection{Inhibition of $N F \kappa B$ transcriptional activity}

In order to check the ultimate effects of NFKB inhibition at transcriptional level, relative mRNA levels of NFKB transcriptional targets were determined by qRT-PCR after LNCaP cells were treated with the indicated concentrations of the molecules w/wo $25 \mathrm{ng} / \mathrm{ml}$ TNF- $\alpha$ for $4 \mathrm{~h}$. Key transcriptional targets of $\mathrm{NF \kappa B}$, which are among important mediators of inflammation-induced carcinogenesis, were investigated. Relative mRNA level of tumor necrosis factor- $\alpha$ (TNF- $\alpha$ ), which is one of the major mediators of inflammation was detected to be induced to 78 fold due to TNF- $\alpha$ treatment. The highest suppression was seen in $\mathbf{5}$ treatment as 46 fold while inhibition by BAY11-7082 at its NFKB inhibitory concentration was 53 fold. Relative mRNA levels due to other molecules were determined as 1 ( 56 fold), 2 ( 49 fold), 3 ( 57 fold), 4 (54 fold), 5 (46 fold). Another transcriptional target, cyclooxygenase-2 (COX2) that activates antiapoptotic, angiogenic, and metastatic 


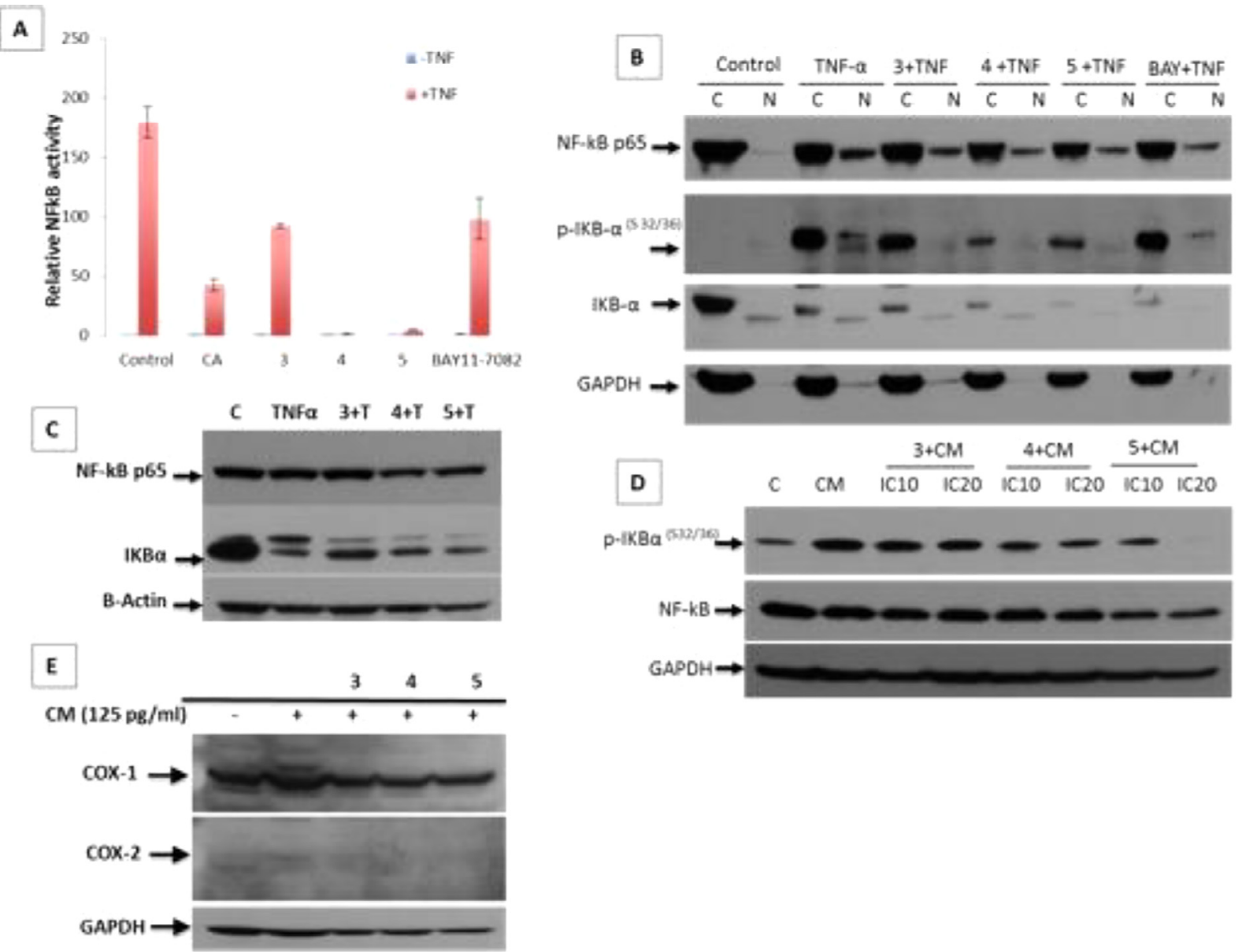

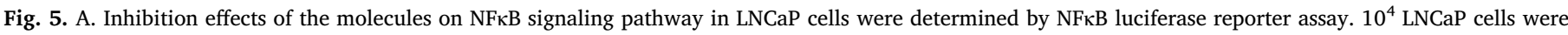

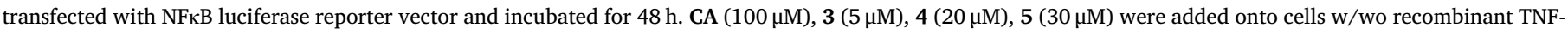

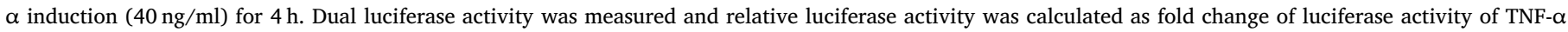

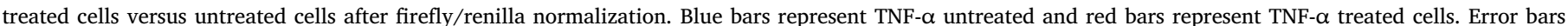

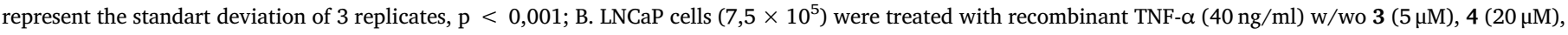

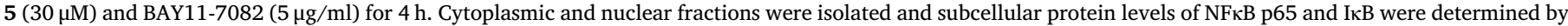

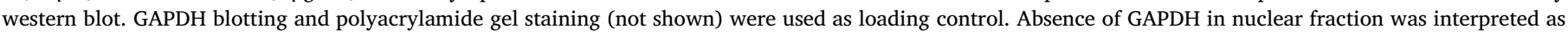

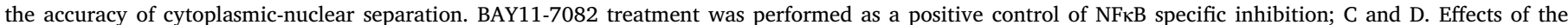

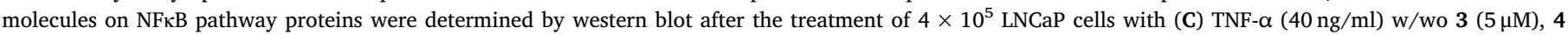

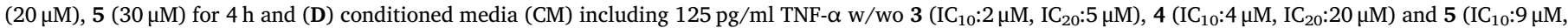

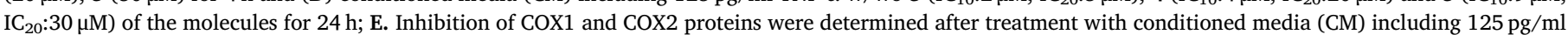
TNF- $\alpha$ w/wo $3\left(\mathrm{IC}_{20}: 5 \mu \mathrm{M}\right), 4\left(\mathrm{IC}_{20}: 20 \mu \mathrm{M}\right)$ and $5\left(\mathrm{IC}_{20}: 30 \mu \mathrm{M}\right)$ for $24 \mathrm{~h}$. B-actin and GAPDH were used as loading controls.

pathways was induced to 12 fold by TNF- $\alpha$ treatment and suppressed to 6 fold by the molecules 1,4 and 5 , whereas 2 and 3 caused 7 and 8 fold suppression, respectively (Bay11-7082: 8 fold). In addition, intercellular adhesion molecule-1 (ICAM1) functioning in migration and invasion of tumor cells was determined to increase 41 fold by TNF- $\alpha$, and suppressed by the compounds (5:17 fold; 1 : 20 fold; 2 : 18 fold; 3: 25 fold; 4: 23 fold; Bay11-7082: 25 fold) (Fig. 6).

\subsection{Inhibition effects on PGE2 release}

This study mainly focuses on the discovery of chemopreventive molecules for inhibition of inflammation-induced tumorigenic alterations; therefore, measurement of Prostagladin E2 (PGE2) is also taken into consideration as it has a driving role in tumorigenic alterations during inflammation. Inhibition of PGE2 release by the compounds was investigated in RAW264.7 macrophages. Cells were seeded in 96-well plates with $4 \times 10^{4} /$ well confluence and incubated for $24 \mathrm{~h}$. Then indicated concentrations of the molecules were applied onto cells with $1 \mu \mathrm{g} / \mathrm{ml}$ LPS concurrently for $24 \mathrm{~h}$ and PGE2 levels were measured in culture media by Elisa. Basal level of PGE2 was detected as $7 \mathrm{pg} / \mathrm{ml}$ in cell culture media and induced to $17.5 \mathrm{pg} / \mathrm{ml}$ by LPS with a subsequent suppression up to $12 \mathrm{pg} / \mathrm{ml}$ by selected compounds. Selective COX2 inhibitor celecoxib was found to suppress the PGE2 level to $9 \mathrm{pg} / \mathrm{ml}$ as a positive control (Fig. 7).

\subsection{Inhibition on prostate cancer cell proliferation}

In order to observe the ultimate effect of NFkB inhibitory activity of the molecules on cell proliferation, LNCaP, PC3 and RWPE1 cells were treated with the NFKB inhibitory concentrations of the molecules, and subjected to Xcelligence real-time cell proliferation system for $48 \mathrm{~h}$. Impedance values detected in every $15 \mathrm{~min}$ for $48 \mathrm{~h}$ were graphed. It was seen that inhibition of NFKB pathway resulted in suppressed cell proliferation in LNCaP cells as well as PC3s with a lower effect. However, proliferation of RWPE1 normal prostate epithelial cells has also been decreased by molecule treatments. Inhibitory effect of CAderived molecules 3, $\mathbf{4}$ and $\mathbf{5}$ was found to be greater than AG-derived $\mathbf{1}$ and $\mathbf{2}$ on all cell lines (Fig. 8). 

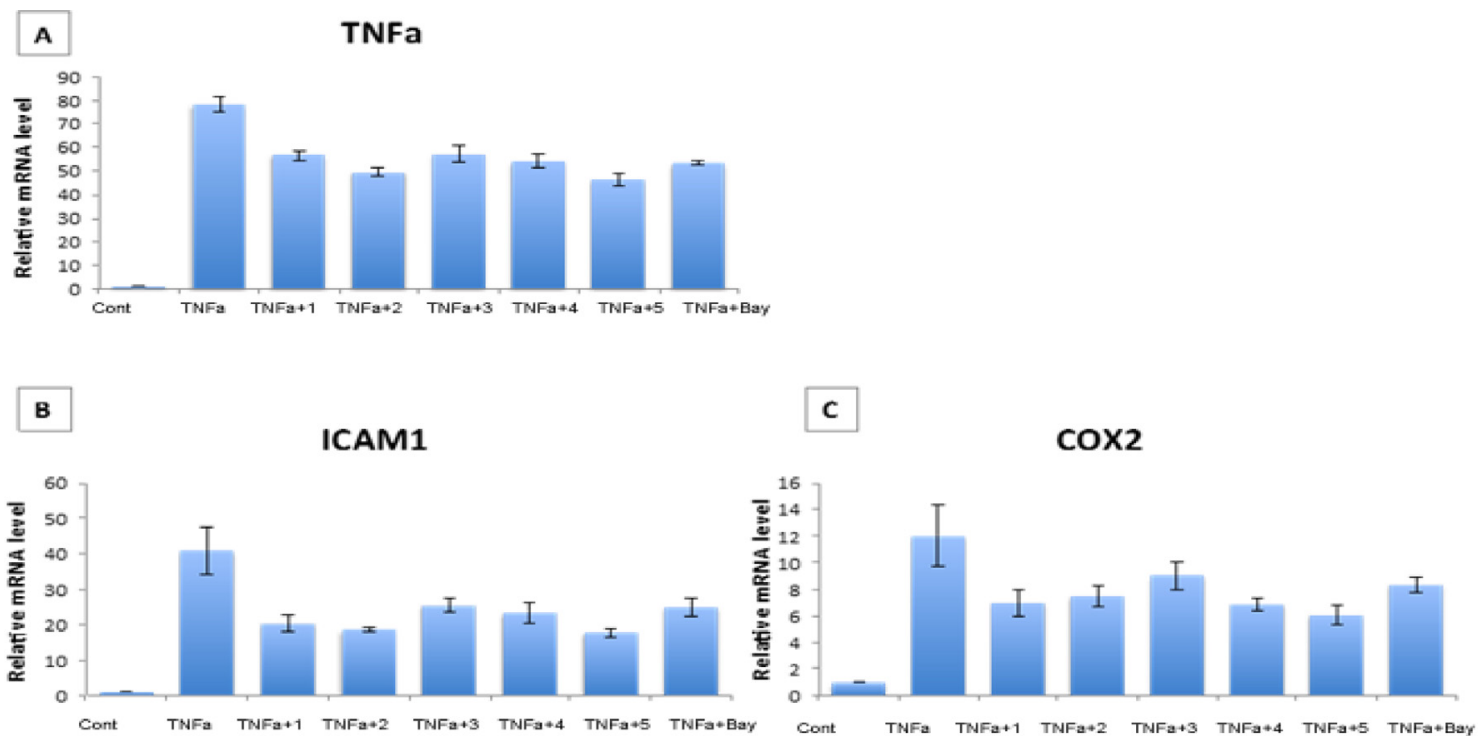

Fig. 6. Relative mRNA levels of (A) TNF- $\alpha$, (B) ICAM1, and (C) COX2 were determined in LNCaPs by qRT-PCR after treatment with TNF- $\alpha$ (40 ng/ml) w/wo the molecules $1,2,3,4$, and 5 for $4 \mathrm{~h}$. The results were analyzed by $\Delta \Delta \mathrm{Ct}$ method, briefly, fold change of treated sample to control was calculated after normalization of target gene to GAPDH. BAY11-7082 $(5 \mu \mathrm{g} / \mathrm{ml})$ treatment was performed as a positive control of NFKB inhibition. Error bars represent the standard deviation of 3 replicates, $\mathrm{p}<0,001$ for molecule treatments with TNF- $\alpha$ vs only TNF- $\alpha$.

\section{PGE2}

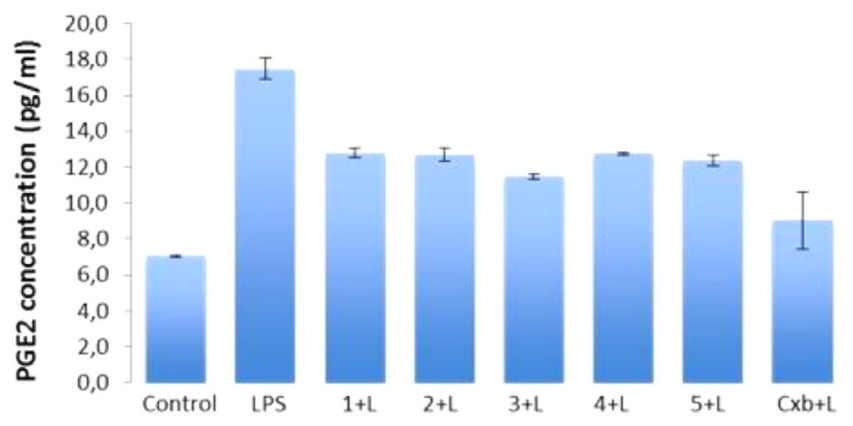

Fig. 7. Inhibition effect of molecules (1:4 $\mu \mathrm{M}, 2: 50 \mu \mathrm{M}, 3: 2 \mu \mathrm{M}, 4: 4 \mu \mathrm{M}$, 5:30 $\mu \mathrm{M})$ on PGE2 levels were determined in RAW264.7 macrophage cells $\left(4 \times 10^{4} /\right.$ well) by Elisa. Induction of PGE2 release by $1 \mu \mathrm{g} / \mathrm{ml}$ lipopolysaccharide (LPS) treatment was performed with simultaneous molecule treatments. PGE2 levels were measured in culture media of the cells after $24 \mathrm{~h}$ treatment. Celecoxib $(1 \mu \mathrm{M})$ was used as positive control. Error bars represent the standart deviation of 3 replicates, $\mathrm{p}<0,001$ for molecule treatments with LPS vs only LPS.

\section{Discussion}

Inflammation and subsequent unbalanced anti-inflammatory response were known to activate tumorigenic mechanisms. Moreover, use of anti-inflammatory drugs was shown to reduce the incidence of many cancer types including colon and prostate by previous studies [28,29]. Therefore, implementation of the right therapy approaches targeting inhibition of inflammation-induced tumorigenic mechanisms has a key interference in treatment of inflammatory diseases. In this study, we aimed to evaluate the potential anti-inflammatory activity of the sapogenol derivatives against prostatic inflammation as a chemo-preventive strategy for inflammation-induced prostate cancer development.

Although cytokine production induced through macrophage infiltration in acute inflammatory microenvironment is suppressed by anti-inflammatory therapy, it is detected that cytokine levels may not be turned to their basal levels for long periods leading to chronic inflammation. In addition, moderate levels of TNF- $\alpha$ induce tumorigenic alterations in contrary to its cellular effects at high levels, which lead to cell death. This uncontrolled and sustained production of TNF- $\alpha$ alters cellular mechanisms functioning in proliferation, apoptosis, angiogenesis and differentiation $[2,7]$. Since NFKB has a regulatory role in all these cellular events, inhibition of NFKB signaling is one of the efficient ways of preventing inflammation-related carcinogenesis. In this study, we showed that the semi-synthetic compounds 1-5 were efficient to prevent NFkB activation stimulated by both recombinant TNF- $\alpha$ and $\mathrm{CM}$ treatment representing inflammatory microenvironment. Interaction of TNF- $\alpha$ with other cytokines in an inflammatory microenvironment also has a significant effect in tumorigenic alterations. Therefore, we used in vitro inflammatory microenvironment model to ensure that our molecules are not only effective on TNF- $\alpha$-induced inflammatory signaling, but also on general pro-inflammatory mechanisms involved by other cytokines.

Effects of the compounds on cell viability were assessed with their $\mathrm{NF \kappa B}$ inhibition results during the evaluation of their anti-inflammatory potentials. Since the NFKB inhibition activity of cycloastragenol-derived molecules were determined to be higher than astragenol-derived molecules at relatively lower concentrations, $3, \mathbf{4}$ and $\mathbf{5}$ were suggested to be promising for treatment of prostatic inflammation and inhibition of $\mathrm{NF \kappa B}$-related tumorigenic activation in prostate cells. In addition, effect of 4 , which was determined as an increase on LNCaP cell viability at first two concentrations, suggested that relatively low levels of 4 enhances cell proliferation opposing to its effect at high concentrations alike TNF- $\alpha$ as explained above.

$\mathrm{NFkB}$ signaling is modulated by many post-translational modifications and many natural products show NFkB inhibition activities by acting on different steps of the signaling cascade. As NFKB has a central role for a wide range of pathologies including inflammation and cancer, drug development studies focused on this pathway and more than 700 of NFKB inhibitors have been identified [30]. Activity mechanisms of many NFkB inhibitors have been characterized and it has been found

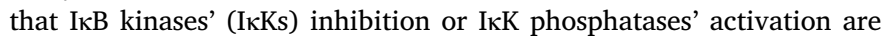
major strategies. In addition, inhibition of IKB proteasomal degradation such as mechanism of bortezomib, inhibition of NFKB acetylation, and inhibition of NFKB nuclear accumulation are further mechanisms identified [31]. In our study, we also showed the inhibition of CM-induced NFKB signaling was achieved by molecules through suppression 


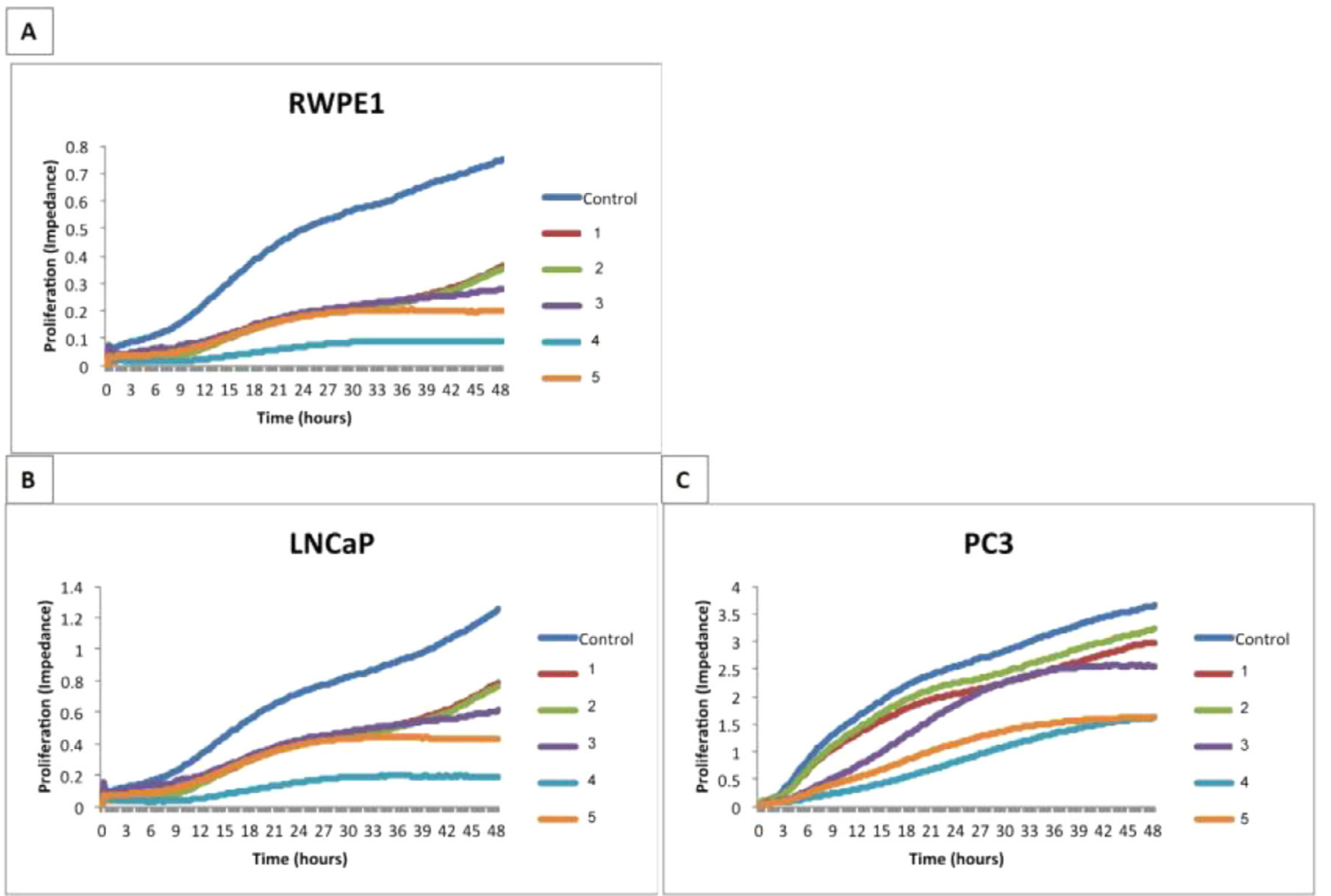

Fig. 8. Inhibition effects of the molecules on proliferation of (A) RWPE1, (B) LNCaP, and (C) PC3 cells at NFkB inhibitory concentrations (1:15 $\mu \mathrm{M}, 2: 50 \mu \mathrm{M}, 3: 5 \mu \mathrm{M}$, 4: $20 \mu \mathrm{M}, 5: 30 \mu \mathrm{M}$ ) were determined by Xcelligence real time cell analysis system. Standard deviation of 5 replicates was calculated at each data point (not shown), $\mathrm{p}<0,001$.

of the IкB phosphorylation. Since, inhibition activity was observed to start at the beginning of the activation cascade, it is suggested that molecules might show this activity through inhibition of IкK kinases and can also interact with IкKs that are responsible from IкB S32/36 phosphorylation [32,33].

The molecules were also detected to decrease the relative mRNA level of COX2, so decrease in PGE2 release is suggested to result from the inhibition of transcriptional activity of NFKB pathway by the molecules and not from a direct inhibition on COX2 activity. Further, adverse effects of non-selective COX inhibitors on gastrointestinal system are known as a limiting factor for anti-inflammatory therapy. Protein levels of COX2 in an inflammatory microenvironment were suppressed by 1, 3, 4 and 5 without COX1 inhibition, which can be an advantage for the use of these molecules as an anti-inflammatory agent with an overall inhibition of tumorigenic mechanisms without side effects of non-selective COX inhibitors [34].

Increase in prostate cancer incidence was ascribed to the western lifestyle in developed countries. Therefore, chemoprevention with dietary agents or plant-derived phytochemicals instead of toxic chemotherapy could be a successful approach in prostate cancer management [29]. Because of the key role of NFKB inhibition for preventing inflammation-related prostate cancer tumorigenesis, many natural products screened for this biological activity. Silibinin and genistein, which are polyphenolic flavonoids and lycopene, which is a carotenoid, have been also reported to target $\mathrm{NF \kappa B}$ pathway and promising molecules for prostate cancer inhibition [29]. Curcumin is another natural molecule in phase II clinical trial for pancreatic cancer [35]. Supporting our data, triterpenoid saponins have also been shown to be efficient on

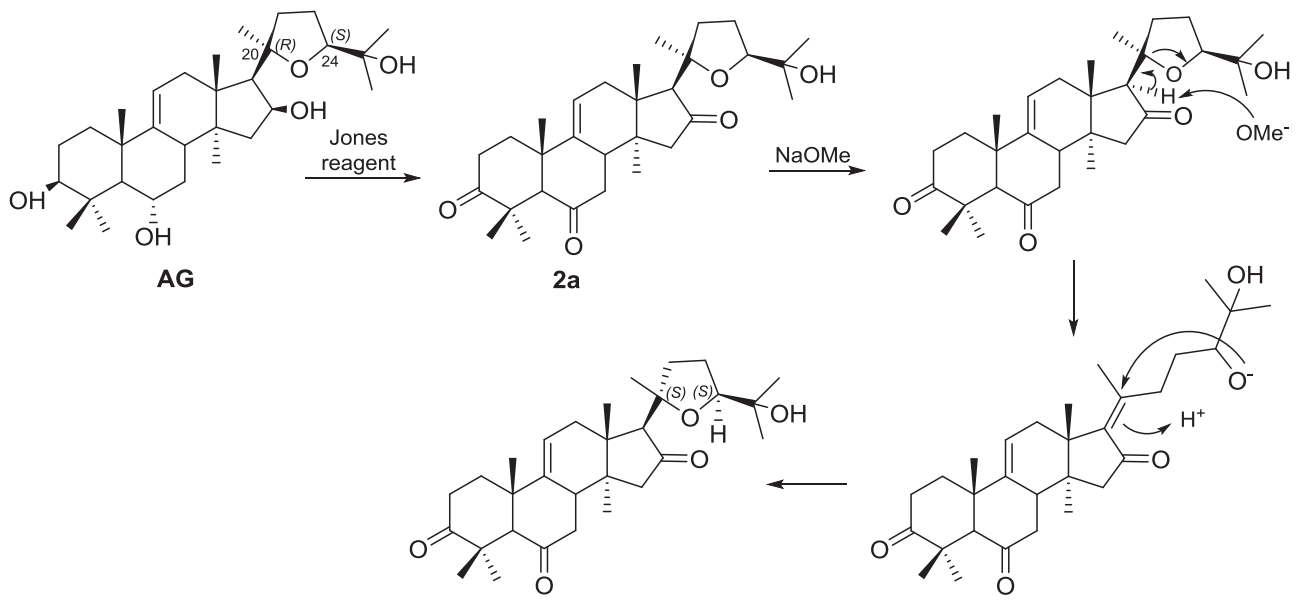

Fig. 9. A plausible mechanism for the synthesis of compound 2 . 
NFкB inhibition previously [36]. The synthetic triterpenoid 2-cyano-3, 12-dioxooleana-1, 9(11)-dien-28-oate (CDDO) was derived from oleanolic acid, and its inhibitory effect on NFKB signaling was shown with ultimate anti-inflammatory and antitumoral activities proving the therapeutic potential $[37,38]$. Furthermore, inhibitory activity of CDDO on $\mathrm{NF \kappa B}$ and tumor formation has been also determined in mouse model of prostate cancer [39].

Most of the drugs approved by FDA are either directly used molecules or modified compounds from plants. Furthermore, more than $60 \%$ of antitumor and anti-infectious drugs already in market or in clinical trials are from natural sources [29]. Since Astragalus saponins have also been reported to have anticarcinogenic effects [40], it has been suggested that astragenol- and cycloastragenol-derived molecules in this study are promising anti-inflammatory agents for prostate cancer chemoprevention and should be further characterized for the possible inhibitory effects on other inflammation-related tumorigenic pathways.

In addition, we would like to draw attention to protein acylation, which is a key post-translational modification in cellular systems. The acyl groups can differ in structure from modified long chain fatty acids to the smallest unit, acetate, all of which can be activated and covalently attached to diverse amino acid side chains such as lysine, cysteine, serine, threonine and $\mathrm{N}$-terminal. Subsequently this covalent modification modulates protein's function. For example, acetylation of lysine residues can change the charge state of proteins leading to new recognition elements for protein-protein interactions. On the other hand, long chain fatty-acylation enables spatial control of cell signaling by targeting proteins to membranes [41]. A few studies report that possessing acyl groups on saponin framework is important for cytotoxicity $[42,43]$. Recently, acetyl salicylic acid (Aspirin) extensively used for its anti-inflammatory, antipyretic, analgesic and anti-thrombotic effects, has been shown to decrease the incidence of cancers of epithelial origin. Studies over the past decades suggest that, besides cyclooxygenases, aspirin acetylates other cellular proteins. Researchers also postulate aspirin's possible acetylation targets as RNA, and metabolites such as CoA, causing a change in their function [44].

From structure activity relationship and mechanism of action perspectives, the following should be taken into consideration. During our screening studies of semi-synthetic cycloartane derivatives, it was realized that acylation of the saponin framework from one or two positions (mainly C-3 and C-6 secondary alcohols) resulted in higher cytotoxicity. Complete activity loss in tri- and tetra-acylated analogs made clear that polarity change towards non-polar compounds was not the overriding basis for the toxicity on cancer cell lines (data not shown). Keeping the recent protein acylation reports in mind, as 1, 3, $\mathbf{4}$ and $\mathbf{5}$ are all acylated analogs, we speculate that these compounds may show their activities via acetylating (in the case of 1, 4 and 5) or propionylating (in the case of 3) protein targets, both of which are post translational modifications occurring in cellular systems. Therefore, for our bioactive acylated compounds, further studies are warranted firstly focusing on acylation hypothesis at global protein level, followed by identifying specific antiinflammatory or novel acylation targets.

\section{Acknowledgments}

This work was supported by Turkish Scientific and Technological Research Council (TUBITAK) with the project number $113 \mathrm{Z} 078$ to BDB.

\section{Appendix A. Supplementary data}

Supplementary data associated with this article can be found, in the online version, at https://doi.org/10.1016/j.steroids.2018.04.005.

\section{References}

[1] K. Kismet, M.T. Akay, O. Abbasoglu, A. Ercan, Celecoxib: a potent cyclooxygenase-2 inhibitor in cancer prevention, Cancer Detect. Prev. 28 (2) (2004) 127-142.
[2] A.J. Schetter, N.H. Heegaard, C.C. Harris, Inflammation and cancer: interweaving microRNA, free radical, cytokine and p53 pathways, Carcinogenesis 31 (1) (2010) $37-49$.

[3] M. Hussain, A. Javeed, M. Ashraf, N. Al-Zaubai, A. Stewart, M.M. Mukhtar, Nonsteroidal anti-inflammatory drugs, tumour immunity and immunotherapy, Pharmacol. Res.: Off. J. Ital. Pharmacol. Soc. 66 (1) (2012) 7-18.

[4] Y. Lin, L. Bai, W. Chen, S. Xu, The NF-kappaB activation pathways, emerging molecular targets for cancer prevention and therapy, Expert Opin. Ther. Targets 14 (1) (2010) 45-55.

[5] B.A. Narayanan, N.K. Narayanan, B. Pittman, B.S. Reddy, Regression of mouse prostatic intraepithelial neoplasia by nonsteroidal anti-inflammatory drugs in the transgenic adenocarcinoma mouse prostate model, Clin. Cancer Res. 10 (22) (2004) 7727-7737.

[6] P. Sooriakumaran, R. Kaba, The risks and benefits of cyclo-oxygenase-2 inhibitors in prostate cancer: a review, Int. J. Surg. 3 (4) (2005) 278-285.

[7] S.P. Hussain, C.C. Harris, Inflammation and cancer: an ancient link with novel potentials, Int. J. Cancer 121 (11) (2007) 2373-2380.

[8] M.J. Morgan, Z.G. Liu, Reactive oxygen species in TNFalpha-induced signaling and cell death, Mol. Cells 30 (1) (2010) 1-12.

[9] A.M. De Marzo, E.A. Platz, S. Sutcliffe, J. Xu, H. Gronberg, C.G. Drake, Y. Nakai, W.B. Isaacs, W.G. Nelson, Inflammation in prostate carcinogenesis, Nat. Rev. Cancer 7 (4) (2007) 256-269.

[10] E.A. Klein, R. Silverman, Inflammation, infection, and prostate cancer, Curr. Opin. Urol. 18 (3) (2008) 315-319.

[11] A.J. Schetter, W.C. You, E.T. Lennette, M.T. Gail, C.S. Rabkin, Association of Epstein-Barr virus antibody levels with precancerous gastric lesions in a high-risk cohort, Cancer Sci. 99 (2) (2008) 350-354.

[12] A.T. Chan, E. Detering, An emerging role for anti-inflammatory agents for chemoprevention, Recent Results Cancer Res. Fortschritte der Krebsforschung. Progres dans les recherches sur le cancer 191 (2013) 1-5.

[13] H.N. Tinsley, W.E. Grizzle, A. Abadi, A. Keeton, B. Zhu, Y. Xi, G.A. Piazza, New NSAID targets and derivatives for colorectal cancer chemoprevention, Recent Results Cancer Res. Fortschritte der Krebsforschung. Progres dans les recherches sur le cancer 191 (2013) 105-120.

[14] D.B. Vendramini-Costa, J.E. Carvalho, Molecular link mechanisms between in flammation and cancer, Curr. Pharm. Des. 18 (26) (2012) 3831-3852.

[15] A. Osbourn, R.J. Goss, R.A. Field, The saponins: polar isoprenoids with important and diverse biological activities, Nat. Prod. Rep. 28 (7) (2011) 1261-1268.

[16] S.G. Sparg, M.E. Light, J. van Staden, Biological activities and distribution of plant saponins, J. Ethnopharmacol. 94 (2-3) (2004) 219-243.

[17] V.R. Yadav, S. Prasad, B. Sung, R. Kannappan, B.B. Aggarwal, Targeting in flammatory pathways by triterpenoids for prevention and treatment of cancer, Toxins 2 (10) (2010) 2428-2466.

[18] A. Nalbantsoy, T. Nesil, S. Erden, I. Calis, E. Bedir, Adjuvant effects of Astragalus saponins macrophyllosaponin B and astragaloside VII, J. Ethnopharmacol. 134 (3) (2011) 897-903.

[19] A. Nalbantsoy, T. Nesil, O. Yilmaz-Dilsiz, G. Aksu, S. Khan, E. Bedir, Evaluation of the immunomodulatory properties in mice and in vitro anti-inflammatory activity of cycloartane type saponins from Astragalus species, J. Ethnopharmacol. 139 (2) (2012) 574-581.

[20] H. W, Isao Kitagawa, Akira Takagi, Masako Fuchida, Iwao Miura, Masayuki Yoshikawa, Saponin and sapogenol. XXXIV. chemical constituents of astragali radix, the root of astragalus membranaceus BUNGE. (1). Cycloastragenol, the 9, 19-cycloanostane-type aglycone of astragalosides, and the artifact aglycone astragenol, Chem. Pharm. Bull. 31 (2) (1983) 689-697.

[21] Ö. Tağ, A. ÇAGIR, A.I. KAHN, E. BEDIR, Cleavage of ring A and formation of an unusual nor-triterpene skeleton via the Baeyer-Villiger reaction, Tetrahedron Lett. 53 (44) (2012) 5864-5867.

[22] H. Calvin, Compositions and methods for skin conditioning, 2005.

[23] I.M.I. Isaev, D.A. Isaev M. I., Triterpene glycosides from Astragalus and their genins, Chem. Nat. Compd. 46 (3) (2010) 407-411.

[24] B. Debelec-Butuner, C. Alapinar, L. Varisli, B. Erbaykent-Tepedelen, S.M. Hamid, C. Gonen-Korkmaz, K.S. Korkmaz, Inflammation-mediated abrogation of androgen signaling: an in vitro model of prostate cell inflammation, Mol. Carcinog. (2012).

[25] D. Gulcemal, M. Masullo, E. Bedir, M. Festa, T. Karayildirim, O. Alankus-Caliskan, S. Piacente, Triterpene glycosides from Astragalus angustifolius, Planta Med. 78 (7) (2012) 720-729.

[26] L. Verotta, M. Guerrini, N.A. El-Sebakhy, A.M. Assad, S.M. Toaima, M.M. Radwan, Y.D. Luo, J.M. Pezzuto, Cycloartane and oleanane saponins from egyptian astragalus spp. as modulators of lymphocyte proliferation, Planta Med. 68 (11) (2002) 986-994.

[27] B. Debelec-Butuner, C. Alapinar, N. Ertunc, C. Gonen-Korkmaz, K. Yorukoglu, K.S. Korkmaz, TNFalpha-mediated loss of beta-catenin/E-cadherin association and subsequent increase in cell migration is partially restored by NKX3.1 expression in prostate cells, PLoS ONE 9 (10) (2014) e109868.

[28] G. Huls, J.J. Koornstra, J.H. Kleibeuker, Non-steroidal anti-inflammatory drugs and molecular carcinogenesis of colorectal carcinomas, Lancet 362 (9379) (2003) $230-232$.

[29] D. Nambiar, R.P. Singh, Advances in prostate cancer chemoprevention: a translational perspective, Nutr. Cancer 65 (Suppl 1) (2013) 12-25.

[30] J. Wilczynski, M. Duechler, M. Czyz, Targeting NF-kappaB and HIF-1 pathways for the treatment of cancer: part I, Arch. Immunol. Ther. Exp. (Warsz) 59 (4) (2011) 289-299.

[31] M. Tafani, B. Pucci, A. Russo, L. Schito, L. Pellegrini, G.A. Perrone, L. Villanova, L. Salvatori, L. Ravenna, E. Petrangeli, M.A. Russo, Modulators of HIF1alpha and NFkB in cancer treatment: is it a rational approach for controlling malignant 
progression? Front. Pharmacol. 4 (2013) 13

[32] S.C. Gupta, C. Sundaram, S. Reuter, B.B. Aggarwal, Inhibiting NF-kappaB activation by small molecules as a therapeutic strategy, Biochim. Biophys. Acta 1799 (10-12) (2010) 775-787.

[33] H.M. Shen, V. Tergaonkar, NFkappaB signaling in carcinogenesis and as a potential molecular target for cancer therapy, Apoptosis Int. J. Program. Cell Death 14 (4) (2009) 348-363.

[34] P.P. Rao, S.N. Kabir, T. Mohamed, Nonsteroidal anti-inflammatory drugs (NSAIDs): progress in small molecule drug development, Pharmaceuticals (Basel) 3 (5) (2010) 1530-1549.

[35] G. Grynkiewicz, P. Slifirski, Curcumin and curcuminoids in quest for medicinal status, Acta Biochim. Pol. 59 (2) (2012) 201-212.

[36] P. Bremner, M. Heinrich, Natural products as targeted modulators of the nuclear factor-kappaB pathway, J. Pharm. Pharmacol. 54 (4) (2002) 453-472.

[37] A.E. Place, N. Suh, C.R. Williams, R. Risingsong, T. Honda, Y. Honda, G.W. Gribble, L.M. Leesnitzer, J.B. Stimmel, T.M. Willson, E. Rosen, M.B. Sporn, The novel synthetic triterpenoid CDDO-imidazolide, inhibits inflammatory response and tumor growth in vivo, Clin. Cancer Res. 9 (7) (2003) 2798-2806.

[38] S. Shishodia, G. Sethi, M. Konopleva, M. Andreeff, B.B. Aggarwal, A synthetic triterpenoid CDDO-Me, inhibits IkappaBalpha kinase and enhances apoptosis induced by TNF and chemotherapeutic agents through down-regulation of expression of nuclear factor kappaB-regulated gene products in human leukemic cells, Clin. Cancer Res. 12 (6) (2006) 1828-1838.

[39] X. Gao, D. Deeb, Y. Liu, A.S. Arbab, G.W. Divine, S.A. Dulchavsky, S.C. Gautam, Prevention of prostate cancer with oleanane synthetic triterpenoid CDDO-Me in the TRAMP mouse model of prostate cancer, Cancers 3 (3) (2011) 3353-3369.

[40] J.K. Ko, K.K. Auyeung, Target-oriented mechanisms of novel herbal therapeutics in the chemotherapy of gastrointestinal cancer and inflammation, Curr. Pharm. Des. 19 (1) (2013) 48-66.

[41] E. Thinon, H.C. Hang, Chemical reporters for exploring protein acylation, Biochem. Soc. Trans. 43 (2) (2015) 253-261.

[42] P.K. Chan, Acylation with diangeloyl groups at C21-22 positions in triterpenoid saponins is essential for cytotoxicity towards tumor cells, Biochem. Pharmacol. 73 (3) (2007) 341-350.

[43] P.K. Chan, M. Zhao, C.T. Che, E. Mak, Cytotoxic acylated triterpene saponins from the husks of Xanthoceras sorbifolia, J. Nat. Prod. 71 (7) (2008) 1247-1250.

[44] L.F. Alfonso, K.S. Srivenugopal, G.J. Bhat, Does aspirin acetylate multiple cellular proteins? (Review), Mol. Med. Rep. 2 (4) (2009) 533-537. 